\title{
From Proposal to Action: Supporting Student Advocacy during Graduate Counseling Training
}

\author{
Britney G. Brinkman \\ Chatham University \\ Keely Hirsch \\ Chatham University
}

\begin{abstract}
Training future clinicians to engage in advocacy is an important element of fostering multicultural competence. We describe the use of an advocacy proposal assignment integrated into a required multicultural counseling course to teach students about advocacy work. We offer data from a study that examined the impact of the assignment on students' perceptions of advocacy/activism. Participants included 74 counseling psychology graduate students. Students in the advocacy compared to the comparison group endorsed greater importance placed on advocacy and greater intentions to engage in advocacy. We also offer four examples of students who moved from the proposal stage to action stage, documenting their projects. Finally, we offer suggestions and recommendations for supporting students' engagement in advocacy.
\end{abstract}

Keywords: advocacy; pedagogy; social justice

(c) 2019 Brinkman \& Hirsch. Free to copy and share for education and scholarship under a Creative Commons Attribution NonCommercialNoDerivatives 4.0 License. 
Social justice advocacy is intended to promote positive change for marginalized and underrepresented groups and is a central tenet in the fields of counseling and counseling psychology (Myers, Sweeney, \& White, 2002). In fact, the American Counseling Association created Advocacy Competencies (ACA) to serve as a framework, and the Multicultural and Social Justice Counseling Competencies (MSJCC) to help clinicians engage in this type of work (Ratts, et al., 2016). Numerous scholars within counseling and psychology have advocated for professionals to engage in social justice work that surpasses traditional multicultural competence models and that emphasizes engagement in advocacy and systems-level interventions (Ali \& Sichel, 2014; Fouad, Gerstein, \& Toporek, 2006; Lewis, Arnold, House, \& Toporek, 2002). For example, the MSJCC explicitly highlight the role of social justice advocacy in counseling modalities. Some have offered excellent examples of advocacy work within the community (e.g., Barrett \& Olle, 2016; Murray \& Crowe, 2016), while others have provided models of engaging students in advocacy in fieldwork (Cook, Krell, Hayden, Gracia, \& Denitzio, 2016). By engaging in advocacy for social justice, systemic inequities that can lead to increased mental health challenges and perpetuate a cycle of oppression can be targeted for change (Ratts \& Hutchinson, 2009). However, for those training future counselors and psychologists, areas of exploration remain. First, while some students enter our programs with existing commitments to social justice and desire to engage in advocacy, many do not. If our intention is to increase the number of counseling professionals engaged in systems level engagement, we must find ways to increase students' interest in advocacy and encourage them to see this work as an aspect of their future professional role. Second, as educators, we should work to facilitate students' transition from interest in advocacy to engagement in this work.

In this paper, we describe the influence of an advocacy-based assignment-within a required multicultural counseling course-on students' views about advocacy. We provide data from a study describing how students' perceptions and commitment to advocacy shifted at the end of the course, compared to students completing an alternative assignment. We also offer four case studies of students who moved from proposal to actionengaging in systems-level activities in a variety of ways. Finally, we offer suggestions and recommendations for supporting students' engagement in advocacy.

\section{Pedagogical Approaches to Advocacy Training}

Education regarding advocacy includes empowering students to engage in social justice by identifying systemic oppressive forces and behavioral responses of clients based on these forces, as well as identifying specific ways to advocate for clients within a system (Ratts \& Hutchinson, 2009).The MSJCC (Ratts, et al., 2016) built upon previous social justice competencies and were developed to highlight how social justice advocacy can be utilized by acting with or on behalf of clients across the micro, meso, and macro levels (Lewis, Arnold, House, \& Toporek, 2002). Such advocacy consists of "institutional intervention skills on behalf of their clients" (Arredondo et al., 1996, p. 3). Becoming knowledgeable about the institutions that create inequalities and injustice for marginalized individuals can lead counselors and psychologists to shift their energy from solely focusing on helping the individual to actively changing the institutions which are themselves the source of problems.

Although courses in multicultural competence and/or social justice are becoming common (Micah, McCreary, \& Walker, 2001; Warren, 2006) and are frequently required in counseling and counseling psychology training programs, the extent to which students receive specific training in advocacy is unclear. One study of over 50 multicultural courses found that only half of them included a specific advocacy assignment (Pieterse, Evans, Risner-Butner, Collins, \& Mason, 2009). Although many of the syllabi in these classes listed social justice as an objective, the application of social justice within the courses was inconsistent-few of them included specific assignments to teach strategies for engaging in social change.

Courses that do utilize advocacy-learning projects to promote social change (Bubriski \& Semaan, 2009) have employed a range of techniques. Most of these courses have used methods such as didactic presentations (Brubaker, Puig, Reese, \& Young, 2010; Singh, 2010), service-learning training programs that include working 
with community-based organizations (Brubaker et al., 2010; Chapdelaine \& Chapman, 1999; Constantine, Hage, Kindaichi, \& Bryant, 2007), and feminist pedagogical strategies (Singh, 2010) to encourage critical reflection and perception transformation (Cetindamar \& Hopkins, 2008). Additionally, instructors can use various pedagogical tools to help students better integrate service learning, such as activities that promote critical reflection (e.g., reflection assignments) (Dunlap, 1998). Some counseling and counseling psychology programs are working to integrate these types of advocacy activities throughout their curriculum. For example, the scientist-practitioneradvocate model (Mallinckrodt, Miles, \& Levy, 2014) was recently introduced as a way to conceptualize graduate training that explicitly integrates social justice advocacy and prepares graduates to address the social contexts of clients' lives.

\section{The Advocacy Proposal Assignment}

The curriculum utilized by training programs is important as it can influence how students think about advocacy and whether they decide to engage in advocacy as part of their professional role. While including in the curriculum service-learning and fieldwork can provide excellent opportunities to engage in advocacy, some students may elect not to participate in these experiences. In particular, students who enter training programs without an existing commitment to social justice, and/or who identify counseling and psychology fields as focusing solely on individual work, may need training that precedes actual participation in advocacy activities. Offering an assignment in required courses that exposes students to the role of advocacy-without requiring them to engage in advocacy-is one way to reach a broad training audience, potentially shift attitudes and commitments toward advocacy, and possibly facilitate a movement towards engagement.

In this paper, we describe an advocacy proposal assignment which was integrated into a required multicultural course where the instructor provided students step-by-step instruction for developing a proposal for a potential advocacy project. The course was a survey style class which addressed issues of culture and identity, as related to counseling and therapeutic relationships. Sociopolitical, socioeconomic, familial, and psychological aspects of diversity, identity, and culture were explored through readings, seminars, and experiential exercises. Students learned about advocacy skills and various ways counselors and psychologists can engage in advocacy with and for clients. Students participating in the treatment sections of the course also completed an advocacy proposal assignment. They were asked to reflect on a form of oppression against one or more groups that occurs at a systemic level within a community to which they belong or had belonged in the past (e.g., the university, the city where they lived, their church, a school they previously attended, etc.). They were required to develop a realistic and specific plan to influence change within that system and address their identified topic. Students wrote a brief paper (8-10 pages) describing the group they selected and literature about the aspect of oppression, a detailed description of the plan and activities they would engage in to facilitate change, expected outcomes and challenges, and resources they would need to implement their plan. Students also participated in a poster session at the end of the semester in which they shared their project idea with their classmates and members of the university community. The poster sessions were open as well to the public and students were welcomed to invite anyone who may have been interested in their project. To date, the lead author has used this assignment in more than 10 sections over seven years, with approximately 15-20 students per section.

The purpose of this research study was to examine how the advocacy proposal assignment impacted students' perceptions of advocacy and their potential commitment to advocacy. Specifically, we used a quasiexperimental approach to compare advocacy-intention outcomes of students who engaged in an advocacy assignment (treatment group) and students who completed a non-advocacy alternative assignment (comparison group). We were interested in two research questions:

1) Did students who completed the advocacy proposal increase in advocacy-intention outcomes from the beginning to the end of the semester?

2) Did students who completed the advocacy proposal differ in their advocacy-intention outcomes from the comparison group at the end of the semester? 


\section{Methods}

\section{Participants}

Participants consisted of graduate students from a small university in the Mid-Atlantic region of the United States. The participants were 74 students enrolled in a required multicultural course as part of their master's level training in a counseling psychology program. They included 65 females, nine males, and zero students who identified as transgender. The majority of the participants self-identified as White, non-Hispanic (75.7\%; 8.1\% African American; 1.4\% American Indian; 2.7\% Asian; 2.7\% Hispanic; 6.8\% multi-ethnic; and $1.4 \%$ other), and heterosexual (94.6\%; 1.4\% Lesbian; $2.7 \%$ Gay male; or $1.4 \%$ Bisexual). The students were predominantly in their first year of their master's program (86.5\% first year; $9.5 \%$ second year; $2.7 \%$ third year; and $1.4 \%$ four or more years) and had a mean age of 26 years (age range: 21 to 58 years, $S D=8.15$ ).

\section{Procedure}

Students were assigned to either a treatment group $(43 \%, N=32)$ or comparison group $(57 \%, N=$ 42) based upon the semester in which they enrolled in the required course. All students in a given section were assigned to the same group (e.g., either treatment or comparison). In order to develop similarly sized groups, data was collected from a total of seven sections (three treatment groups, four comparison groups) of the same course offered over two years (including summers). Sections ranged from eight to 18 students (as is typical for the master's program in which the students were enrolled). All sections of the course were taught by the same instructor (the Principal Investigator [PI] and first author). All students were asked to volunteer for the study on the first day of their class. Students in both groups were told that the purpose of the study was to "examine counseling psychology students' development of multicultural competence and commitment to activism and advocacy work." Students were unaware there was a treatment and comparison group in the study. The instructor informed the students about the study and explained that their participation was completely voluntary, confidential, and that participation would not influence their grade. A research assistant distributed and collected consent forms and participants were given code numbers. The professor did not learn who participated in the study until after the end of each semester. Students in both groups completed a demographics form and advocacy questions on their first day of class prior to starting the lesson. At the end of each semester, students completed the advocacy questions. Sixty students completed both the pre- and post-test questions. The Institutional Review Board at the PI's university approved all procedures for the study.

\section{Multicultural Case Conceptualization}

Students in the comparison group were provided with hypothetical cases of clients. Students were asked to choose one case and answer questions regarding: case conceptualization focusing on multicultural aspects, how students might respond to the client, and what additional information was needed to work with the client. The case conceptualization paper was utilized for the comparison group to ensure that both groups completed similar amounts of work for the course. Case conceptualization papers are a common assignment utilized in the master's program the students were enrolled in and could be considered the standard of teaching for this program.

The difference in the instruction of the two courses included three class sessions. At two points in the semester, during the 3-hour class session, one hour was designated for an "advocacy project workshop" for the treatment group, while the comparison group spent one-hour in a "case conceptualization workshop." On the final day of class, the treatment group held a poster presentation, where students displayed their advocacy proposals. The comparison group, in contrast, on the final day of class participated in a large group discussion/ wrap up of the semester.

\section{Measures}

Demographic Questionnaire. A short demographic questionnaire was used to assess participant age, gender, sexual orientation, year in program, and ethnicity. 
Advocacy in Counseling Questionnaire. The questionnaire and items for this study was created by the PI based on the literature on the development of advocacy and/or activism intentions and behaviors. There is no validity or reliability data available for this measure. Participants responded to three statements about the role of activism/advocacy in counseling. Students were prompted to indicate their level of agreement with each statement using a Likert response format ranging from $1=$ strongly disagree to $4=$ strongly agree. The three statements included: 1) "Engaging in activism and/or advocacy is an important part of developing multicultural competence as a counselor;" 2) "I feel confident in my ability to engage in activism and/or advocacy regarding multicultural issues;" and 3) "I intend to engage in activism and/or advocacy in my future role as a counselor (or counselor-in-training)." Students also were asked to explain their level of agreement with each statement, using an open-ended format. The responses ranged from 1-3 sentences and were analyzed using qualitative content analysis (as described below).

\section{Qualitative Data Analysis}

Qualitative Content Analysis (QCA; Altheide, 1987; Tashakkori \& Teddlie, 1998; Thomas, 2003) was used to analyze the responses to the open-ended questions, developing the codes based on the responses of the participants, rather than being imposed by the researcher. QCA is an inductive method that allows the researcher to develop new categories throughout the coding procedure using constant comparative analysis. Two independent coders analyzed the qualitative responses obtained in the study (a female psychology undergraduate and a female psychology graduate student), with the PI overseeing the coding process. The coders were trained by the PI to engage in qualitative content analysis. The coders were trained in person, over multiple meetings, lasting approximately 10 hours. The coders were provided with information about qualitative content analysis and walked through examples of coding from this framework. The coders were encouraged to email the PI with any questions about the process. The coders met with the PI at the end of each stage of the coding to review the data and the coding process. In the initial stage of coding, the coders utilized open coding to break down the data into concepts or units of meaning (Fassinger, 2005). In this stage, the coders independently read the responses and created their own categories that emerged from the data. After this stage, the coders met with the PI and compared their initial lists to create a shared list. The two coders then independently coded the data using the shared coding list. The coding lists and definitions of codes were revised until the inter-rater reliability for each category (using Cohen's kappa) was above .50 which is considered a moderate value according to Altman (1991), with all but one category (confidence) being .60 or higher. In the final stage, any discrepancies between the coders were resolved through consensus and the final coded data were developed.

\section{Results}

\section{Change-over-time}

First, we wanted to understand whether students who completed the advocacy proposal increased in advocacy-intention outcomes from the beginning to the end of the semester. On both the pre-test and post-test questionnaires, students were asked to indicate their level of agreement with three statements about activism and/or advocacy utilizing a Likert response format. We compared the treatment group's scores from pre-test to post-test. We first assessed whether students felt that activism and/or advocacy is an important part of developing multicultural competence as a counselor by asking them to indicate their level of agreement with the statement, "Engaging in activism and/or advocacy is an important part of developing multicultural competence as a counselor." Based on a paired samples dependent $t$-test, the treatment group significantly increased in the Likert rating from pretest $(M n=3.15 ; S D=.67)$ to post-test $(M n=3.62 ; S D=.57), t(25)=3.33, p<.01$.

We next assessed students' self-assessment of their confidence in their ability to engage in advocacy or activism by asking them to indicate their level of agreement with the statement, "I feel confident in my ability to 
engage in activism and/or advocacy regarding multicultural issues." Based on a paired samples dependent $t$-test, the treatment group significantly increased in the Likert rating from pretest $(M n=2.92 ; S D=.80)$ to post-test $(M n=3.42 ; S D=.50), t(25)=2.96, p<.01$.

To explore students' plans to engage in advocacy, we asked them to indicate their level of agreement with the statement, "I intend to engage in activism and/or advocacy in my future role as a counselor (or counselorin-training)." Based on a paired samples dependent $t$-test, the treatment group did not significantly increase in the Likert rating from pretest $(M n=3.27 ; S D=.53)$ to post-test $(M n=3.42 ; S D=.64), t(25)=1.28, p=.21$. See Table One for a list of all pre-test and post-test means for the treatment and comparison groups.

Table 1: Means of pretest and posttest advocacy intention scores for treatment and comparison groups Pretest

Posttest

\begin{tabular}{lcccc} 
Measure & Treatment & Comparison & Treatment & Comparison \\
\hline Importance & $3.15_{\mathrm{a}}$ & $3.26_{\mathrm{a}}$ & $3.62_{\mathrm{b}}$ & $3.57_{\mathrm{b}}$ \\
Confidence & $2.92_{\mathrm{a}}$ & $2.89_{\mathrm{a}}$ & $3.42_{\mathrm{b}}$ & $3.22_{\mathrm{b}}$ \\
Intentions & $3.27_{\mathrm{a}}$ & $3.26_{\mathrm{a}}$ & $3.42_{\mathrm{a}}$ & $3.68_{\mathrm{a}}$ \\
\hline
\end{tabular}

Note: Within each row, means with different subscripts are significantly different from one another at the $p<.01$ level.

\section{End-of-course outcomes}

Next, we examined whether there were differences in the end-of-course advocacy intentions between the treatment and comparison group. Based on paired samples independent $t$-tests, there were no significant differences on the Likert ratings at pre-test or post-test between the treatment group and the comparison group.

Next, we examined whether students from the two groups differed in the qualitative data generated from the open-ended responses. For each statement, several categories emerged from the qualitative data. There were no pre-test differences between the treatment group and comparison group for any of the categories. Chisquare analyses were conducted to assess for differences between the groups at post-test. As we were particularly interested in students' responses following their participation in the course, we only report the frequencies and percentages for the codes at post-test. Not all students wrote about all themes and some students wrote about multiple themes, so the percentages do not necessarily total $100 \%$.

First, we examined the open-ended responses related to the statement: "Engaging in activism and/or advocacy is an important part of developing multicultural competence as a counselor." Three categories emerged from the students' explanations of their level of agreement with this statement: advocacy is important, advocacy impacts counselor, advocacy impact society. See Table 2 for list of codes and frequencies. 
Table 2: Students' responses to "Engaging in activism and/or advocacy is an important part of developing multicultural competence as a counselor"

\begin{tabular}{|c|c|c|c|c|c|}
\hline \multirow[b]{3}{*}{ Category } & \multirow[b]{3}{*}{$\begin{array}{c}\text { Frequency of } \\
\text { category }\end{array}$} & \multicolumn{4}{|c|}{ Students who endorsed category } \\
\hline & & \multicolumn{2}{|c|}{ Comparison group } & \multicolumn{2}{|c|}{ Treatment group } \\
\hline & & $N$ & Percentage (\%) & $N$ & Percentage (\%) \\
\hline Advocacy is important & 25 & 1 & 45.2 & 24 & 75.0 \\
\hline \multicolumn{6}{|l|}{ Advocacy impacts Counselor } \\
\hline understanding knowledge & 15 & 9 & 21.4 & 6 & 18.8 \\
\hline Competence & 5 & 3 & 7.1 & 2 & 6.3 \\
\hline Awareness & 4 & 2 & 4.8 & 2 & 6.3 \\
\hline Open-minded & 2 & 2 & 4.8 & 0 & 0.0 \\
\hline Advocacy impacts society & 17 & 9 & 21.4 & 8 & 25.0 \\
\hline
\end{tabular}

Chi-square analysis was conducted to examine whether students who completed the advocacy project differed in their endorsement of the importance of advocacy from students in the comparison group, meaning that in their written response they indicated that advocacy was important. At post-test, the students in the treatment group $(n=24,75 \%)$ were significantly more likely than the students in the comparison group $(n=$ $19,45.2 \%)$ to indicate that advocacy is important, $\chi^{2}(1,74)=6.61, p<.001$, Cramer's $\mathrm{V}=.30$. There were no significant differences between the groups at post-test for any of the other categories.

Within the category of advocacy impacts counselor, students indicated that activism/advocacy was important because it impacts a counselor in their level of awareness, increases their understanding or knowledge, was related to competence, and increases open-mindedness or expands their perspectives. One student wrote, "Being active and advocating for what is right makes us better counselors by broadening our awareness and increasing sensitivity to issues that impact our clients." In their explanation of why advocacy was important, some students wrote about ways advocacy impacts society as a whole. These answers included comments about having an influence on people other than clients as well as working outside the traditional counselor-client relationship. One student commented, "Advocating for our clients/potential clients exhibits abundant levels of care for the well-being of the community."

Next, we examined the open-ended responses to the statement: "I feel confident in my ability to engage in activism and/or advocacy regarding multicultural issues." Four categories emerged from the students' explanations of their level of agreement with this statement: confidence, past or current experience, interest, and what is needed to build confidence. See Table 3 for list of codes and frequencies. 
Table 3: Students' responses to "I feel confident in my ability to engage in activism and/or advocacy regarding multicultural issues"

\begin{tabular}{|c|c|c|c|c|c|}
\hline \multirow[b]{3}{*}{ Category } & \multirow[b]{3}{*}{$\begin{array}{c}\text { Frequency of } \\
\text { category }\end{array}$} & \multicolumn{4}{|c|}{ Students who endorsed category } \\
\hline & & \multicolumn{2}{|c|}{ Comparison group } & \multicolumn{2}{|c|}{ Treatment group } \\
\hline & & $N$ & Percentage (\%) & $N$ & Percentage (\%) \\
\hline \multicolumn{6}{|l|}{ Past or Current Experience } \\
\hline Yes & 17 & 7 & 16.7 & 10 & 31.3 \\
\hline No & 2 & 2 & 4.8 & 0 & 0.0 \\
\hline \multicolumn{6}{|l|}{ Confidence } \\
\hline Confident & 12 & 8 & 19.0 & 4 & 12.5 \\
\hline Confident about some issues & 10 & 6 & 14.3 & 4 & 12.5 \\
\hline No confidence & 2 & 2 & 4.8 & 0 & 0.0 \\
\hline Interest & 10 & 5 & 11.9 & 5 & 15.6 \\
\hline \multicolumn{6}{|c|}{ What is Needed to Build Confidence } \\
\hline Only Knowledge & 7 & 5 & 11.9 & 2 & 6.3 \\
\hline Both knowledge and skills & 3 & 1 & 2.4 & 2 & 6.3 \\
\hline Only Skills & 1 & 1 & 2.4 & 0 & 0.0 \\
\hline
\end{tabular}

Chi-square analyses were used to examine whether there were differences in the level of confidence between students in the treatment and comparison groups. No significant differences were found between the treatment group $(n=4,12.5 \%)$ and the comparison group $(n=8,19 \%)$ in the students who directly endorsed feeling confident. There were also no significant differences found between the treatment and comparison group in the three other categories. These findings should be interpreted with caution, however, given the low $n s$ of these groups.

To explain their degree of endorsement of whether they felt confident, many students referred to their own experience (past or current) of doing activism or advocacy. Some students indicated they had interest in doing advocacy work, sometimes despite their lack of experience. For example, one student noted, "I feel passionate about different issues however I haven't had the chance to really engage these yet." A number of students also wrote about what they would need in order to have greater confidence, including more knowledge, more skills, and more overall experience (including both skills and knowledge).

Finally, we examined the open-ended responses regarding the level of agreement with the statement: "I intend to engage in activism and/or advocacy in my future role as a counselor (or counselor-in-training)." Chi-square analyses indicated that students in the treatment group $(n=20,63 \%)$ endorsed significantly more intentions to engage in advocacy than did students in the comparison group $(n=14,33 \%), \chi^{2}(2,74)=8.32, p$ $<.05$, Cramer's $\mathrm{V}=.34$. These responses were coded into two categories: intend to engage in advocacy and do not intend to engage in advocacy. Many of these students stated their plans unequivocally, "I definitely plan on advocating for others." One student commented, "I really feel that it is a necessary part of my job as a counselor to advocate for clients both inside and outside the counseling room." Some students indicated that they would engage in advocacy under the right conditions or that they were willing to try. 


\section{Advocacy in Action}

In this section, we describe four examples of student case projects that began within the course as an advocacy proposal and turned into action in some form. All students provided written permission to have their project described in this publication (including their names). One student requested that their project remain anonymous, as they were working on advocating within their workplace and the project was ongoing. The four projects were intentionally selected to provide a breadth of understanding of the different forms that advocacy projects took and how some unfolded in ways that were very similar to what was originally proposed, while in other cases the proposal assignment led to other engaged work.

\section{Preventing Sexual Violence on College Campuses}

Carol Balk, M.S. was concerned about sexual violence on college campuses and wanted to see more prevention work happening that engaged bystanders in creative ways. Carol learned about the Circle of 6 App (https://www.circleof6app.com/), a smartphone application designed to facilitate access to a "circle" of supportive individuals - when needed-for help. With the support of the first author, Carol met with student affairs staff to describe her proposal to bring the App to campus. A collaborative project developed between the Graduate Psychology department and an Assistant Dean of Students. The purpose of the Community Building and Violence Prevention project was to pilot a program designed to decrease sexual assault and other forms of interpersonal violence through bystander intervention and the use of the Circle of 6 App. The project included development and implementation of a workshop introducing students to bystander intervention and the use of the App. Over 100 undergraduate students participated in the workshops. The project included a research study examining the efficacy of the workshops, use of the App, and how students engaged in discussions of sexual violence (See Author A, under review).

\section{Intergroup Dialogues}

David Williams, M.A., and Kathleen Fawcett, M.S. proposed bringing the Intergroup Dialogue (Michigan model) program to the university. Research on the Michigan model of intergroup dialogue has been found to increase students' understanding of group-based inequalities, increase students' awareness and understanding of social identities, and increase students' positive intergroup relationships, especially their motivation to bridge differences (Gurin, Nagda, \& Zuniga, 2013). David and Kathleen proposed bringing the model with some adaptations to make it appropriate for the school. After numerous meetings with administrators in academic affairs and student affairs (including department chairs, deans, and others), the university agreed to support and fund a pilot implementation of the program, which is currently ongoing. The students, especially David, stayed involved throughout the process, even presenting on the work at the American Psychological Association convention (Paquin \& Williams, 2017). When asked to be included in the current project, David commented about the advocacy proposal:

"I think the advocacy assignment is an excellent activity. It helps orient students to the idea that psychology is really about working on an individual as well as community basis and, in many cases, it forces students to establish connections with their community. The advocacy project connects the academic material with real life situations of misunderstanding and/or inequality."

\section{Student Athletes and Mental Health}

Amanda Halula and a classmate believed that student athletes frequently go untreated for mental health concerns because of the stigma related to seeking help. Their project highlighted ways identities as athletes often intersect with gendered identities and stereotypes to exacerbate concerns. For example, elite female athletes may be judged on their physical appearance more than their athletic ability, while also being at increased risk for developing eating disorders. Amanda and her classmate proposed addressing these concerns by raising awareness on their campus, increasing the relationship/collaboration between counseling services and the athletic 
department, and developing educational material for various audiences. Although they did not implement their proposal, Amanda did go on to work with a faculty member and other students in developing a grant proposal, which was funded by the National Collegiate Athletic Association (NCAA), to create a web-based program that will train coaches in ways to communicate with athletes about mental health topics and how to make appropriate referrals when needed. When asked to be included in the current paper, Amanda commented,

"I would definitely say that the advocacy project helped with writing our grant later on. Although the project had its own guidelines to follow and fulfill, it allowed me to begin articulating my areas of interest and funnel my ideas into concrete objectives and programming. I would definitely say that the advocacy project created a spring board for later opportunities."

\section{Paid Parental Leave}

The final example includes a student who was working full time while going to school. The student (who I will refer to as "G" as they chose to remain anonymous) recently discovered that their workplace did not have a paid parental leave policy, which they found to be surprising given the nature and publicly espoused values of the place of employment. $G$ was concerned about the lack of paid paternal leave and the burden this placed, especially on single mothers. For this project, $G$ learned about various paid leave policies and laws in the region and nation, as well as research on the benefits of having such policies. G started to explore the history of the policy within their workplace and who the important change makers would be. G was surprised to find that raising the issue of paid paternal leave was controversial and $G$ treaded carefully, while advocating for a change to the policy. At the time of this writing, G reported that progress had been made, but their organization recently had a significant leadership change, so the outcome was uncertain.

These examples were intentionally chosen to showcase a variety of approaches students have taken over the years. Contrary to the examples, most students did not propose campus-based projects (although some did). However, campus-based projects have been the most likely ones to be implemented as close to their proposal form and while the student is still in school. This is not surprising given that graduate students spend a great deal of time on campus and may more easily find collaborators within the campus community than outside it. However, it is our hope that students take the skills they develop from this project into a variety of community settings and apply them throughout their career.

\section{Discussion}

There were two research questions posed for this study. The first question examined whether students who completed the advocacy proposal changed over the course of the semester. Findings from the quantitative data indicated that the students in the treatment group increased from the beginning to the end of the semester in their endorsement of the importance of advocacy and their confidence to engage in advocacy. Our second research question was designed to examine whether students in the treatment group differed from students in the comparison group in their advocacy-intention outcomes at the end of the semester. Students from the treatment group and comparison group did provide meaningfully different responses on the qualitative measure. Students in the treatment versus the comparison group were significantly more likely in their responses to indicate that advocacy was important, and that they intended to engage in advocacy work. Our findings suggested that completing an advocacy proposal project may be impactful on students' attitudes about advocacy and intentions to engage in advocacy. For example, in response to the question about whether advocacy was important, students in the treatment group indicated that it is important because it can have a broad impact on society and also impact the counselor's development of competence and self-awareness. The qualitative data also provides insights about what the students would need to feel more confident in their ability to engage in advocacy. Students reported that they needed more knowledge, more skills, and more experience to feel confident in engaging in advocacy. 
Our findings contribute to the existing literature regarding pedagogical tools for training students in advocacy by offering an alternative to service-learning approaches. While service-learning opportunities and engaged advocacy through fieldwork can be great ways of developing advocacy skills in students, these approaches do have limitations. In their interviews with 67 community organization representatives who work with servicelearning students, Tryon and Stoecker (2008) found that many reported numerous challenges including: lack of cultural competency, communication and relationship-building, and challenges associated with short-term service-learning projects. Utilizing an advocacy proposal project like the one discussed in the current article, which students are not required to complete, may be a useful way to encourage students' developmental process regarding advocacy work, while combatting these limitations.

Although our findings suggest that students in the treatment group increased in their advocacyintention outcomes at the end of the semester, it is important to note that the findings for the quantitative and qualitative data were mixed with respect to the treatment and comparison groups. While there were differences in the qualitative data, students in the two groups did not differ on any of the quantitative items at post-test. More research is needed to better understand how students are impacted by completing an advocacy proposal assignment, compared to learning about advocacy without engaging in such an assignment. It is possible that learning about advocacy within a multicultural course is sufficient to impact students' attitudes regarding advocacy.

The four case studies we describe in this paper can help to elucidate the process that students undergo when they decide to put an advocacy idea into action. The students in the current study were able to build upon their assignment and, with additional support and guidance, implemented their project or a similar one. These case studies suggest that the advocacy assignment may be of utility for students who are already committed to social justice and ready to move toward action. In addition to having a positive impact on their chosen community, the students who do engage in advocacy action may experience direct benefits. Recent research has demonstrated that engaging in service-learning or advocacy work in conjunction with courses can increase students' multicultural competency and advocacy-related skills. In general, one meta-analysis found that components of service learning can lead to positive changes for students, including academic, personal, and social outcomes (Conway, Amel, \& Gerwien, 2009). Future research should examine in-depth the experiences of counseling students doing advocacy projects to better understand the most effective pedagogical tools for instructing these individuals.

\section{Limitations}

There are several limitations to our study, and therefore, we recommend interpreting the findings with caution. First, there is no data available regarding the validity or reliability for the quantitative advocacy in counseling measure we administered. The items on this scale were developed by the PI for the purpose of this study. The intention of the measure was to examine participants' thoughts about advocacy. The three areas assessed by this scale (i.e.., whether advocacy is important; confidence to engage in advocacy; and intentions to engage in advocacy) were chosen based on the literature. The Likert response formats linked with the items were used to help the students anchor their quantitative responses. Each item was intended to stand alone, and they were not intended to be combined into a scale. The quantitative findings should be interpreted with caution given the limitations just mentioned.

The students who participated in this research study, and most of the students in the targeted training program, identify as White, heterosexual, cisgender females. This leads to limitations both of the study and in terms of drawing conclusions about how the particular advocacy proposal activity described in this article impacts students. In general, the lack of diversity within the selected classes may have prevented a greater depth of discussion about cultural diversity and may have influenced how students conceptualized advocacy.

Furthermore, while the two different classes/groups (treatment and comparison) had the same instructor 
and curriculum (except for the different projects), the two classes differed in terms of the composition of individuals and discussions that occurred. These differences, among other non-controlled factors (e.g., the semester in which the course was taken) may have influenced students' perceptions about advocacy and their motivation to engage in this type of work.

Additionally, while measures were taken to reduce experimenter bias (have a research assistant collect data from participants), the fact that the PI taught the classes could have influenced how she presented advocacy to the different classes. Future research should include an instructor that is blind to the research questions. Additional research also could examine how students' own social identities influence their conceptualization of and engagement in advocacy. Moreover, future research should explore the developmental trajectory for students as they engage in advocacy work both as a student and when they enter into their careers. This research could shed additional light on the barriers that students face in moving from valuing advocacy to including it in their own work. Obtaining this information could help training programs to increase their support for students interested in advocacy activities.

\section{Recommendations}

Based on the results of this study and our professional experiences, the following are recommendations that can support students who want to move from the proposal to action stage. These recommendations, however, should be considered with caution, as future research is needed to attempt to replicate the current findings, and to further investigate how to best engage students in advocacy activities.

1. Provide an opportunity for students to showcase their proposals. Based on the findings of this study, we found that holding a public poster session (or similar activity) as part of the course requirements can help students in numerous ways. It gives them an opportunity to discuss their project with others, they can invite stakeholders to the poster session to begin discussions about implementation, and they can bring the poster with them to meetings where they are presenting their idea.

2. Assist students in finding collaborators and allies. Additionally, we found that it was important (and often necessary) for students to connect with faculty members and/or other university staff who would collaborate with them and support their projects. In the first three student case examples highlighted earlier, one or more faculty/staff members became involved early on in the project and held pivotal roles. This can be important for numerous reasons: a) these individuals may have access to resources/social capital that students do not; b) these persons can provide ongoing mentoring to students so they can continue to learn throughout the process; and c) these individuals can sustain a project when a student graduates. Many advocacy projects take on a life and timeline of their own, often moving at a pace that is different from a student's graduation timeline. While the four student case examples discussed in this article focused on the university community, this is also true of partnerships with other organizations within the community. Langseth (2000) argued that long-range community change and the most effective multicultural education for students result from high trust and high investment relationships between universities and communities. These relationships take time and may develop outside of the course of one student's career. Ideally, an individual student will stay involved in a project after graduation and will continue to lead (or at least influence) the project. This has been the case with the four student case examples in this paper. Even in these circumstances, permanent faculty and staff members can be helpful in sustaining a project and supporting a student's role transition.

3. Encourage students to integrate advocacy with research. Based on the four presented student case studies, we propose that it may be helpful for students to integrate advocacy with research projects. One way to support students incorporating research into their advocacy project would be to recruit faculty collaborators who can work on the project as part of their own research agenda. Community-based 
participatory action research (CBPAR) is a collaborative approach to research that equitably involves all partners in the research process. The goal is to ensure that the topic is of interest to the community and that these projects combine knowledge and action for social change to improve community wellbeing (W.K. Kellogg Foundation). Conducting ongoing research on an advocacy project can contribute to ensuring that the project is effective and meaningful to the relevant population. By incorporating research into an advocacy project, it may be possible to shed light on disparities within our society and also provide evidence to support advocacy efforts.

\section{Conclusion}

Recent calls have encouraged counseling and counseling psychology to incorporate macro-level interventions focused on promoting social change and advocacy or activism (Beer, Green, Spanierman, \& Todd, 2012; Singh, 2010; Vera \& Speight, 2003). In order for students and professionals to heed these calls, training programs need to find effective ways to integrate advocacy education into their multicultural and social justice pedagogy. This includes offering training that recognizes the spectrum of students' readiness. Some students enter our programs with an existing commitment to social justice work and they are eager for opportunities to engage in advocacy. Others enter our programs with the intention of focusing solely on individual change models and may have never considered the possibility of engaging in systems-based interventions. Frequently, as instructors, we encounter a classroom full of students who exist at a variety of places on this spectrum. It is our job, however, to offer creative, engaging, and effective techniques and learning opportunities for everyone in our classes.

The advocacy proposal assignment discussed in this article is one way to engage all students in considering the role of advocacy within their professional lives and to provide them with the tools to prepare them to engage in this type of work. Students who are unsure about advocacy or for whom this material is new can use the assignment to learn more about the importance of structural-level interventions. Students who are ready to transition from proposal to action can be supported by having an opportunity to showcase their advocacy ideas and by being connected with collaborators and allies who will work with them to put their plans in motion.

\section{Corresponding author}

Britney G Brinkman is now at Point Park University. Keely Hirsch is now at Kaiser Permanente. Please address correspondence about this article to Britney G Brinkman, Point Park University, 201 Wood Street, Pittsburgh, PA, 15222. Email: bbrinkman@PointPark.EDU.) 


\section{References}

Altheide, D. L. (1987). Reflections: Ethnographic content analysis. Qualitative Sociology, 10(1), 65-77. doi:10.1007/BF00988269

Altman, D. G. (1991). Mathematics for kappa. Practical Statistics for Medical Research. London: Chapman \& Hall.

Arredondo, P., Toporek, R., Brown, S. P., Jones, J., Locke, D. C., Sanchez, J., \& Stadler, H. (1996). Operationalization of the multicultural counseling competencies. Journal of Multicultural Counseling and Development, 24, 42-78. doi:10.1002/j.2161-1912.1996.tb00288.x

American Counseling Association. (2003). Guidelines on multicultural education, training, research, practice, and organizational change for psychologists. American Psychologist, 58, 377-402. doi:0.1037/0003066X.58.5.377

Barrett, J. G., \& Olle, C. D. (2016). Social justice training in action: A counseling psychologist's role in a police-mental health collaborative serving disadvantaged youth. Journal for Social Action in Counseling and Psychology, 8, 13-31.

Beer, A.M., Greene, J.C., Spanierman, L.B., \& Todd, N.R. (2012). Counseling psychology trainees' perceptions of training and commitments to social justice. Journal of Counseling Psychology, 59, 120-133. doi: $10.1037 / \mathrm{a} 0026325$

Brubaker, M.D., Puig, A., Reese, R.F., \& Young, J. (2010). Integrating social justice into counseling theories pedagogy: A case example. Counselor Education \& Supervision, 50, 88-102. doi:10.1002/j.1556-6978.2010.tb00111.x

Bubriski, A., \& Semaan, I. (2009). Activist learning vs. service learning in a women's studies classroom. Human Architecture; Journal of the Sociology of Self-Knowledge, 7, 91-98.

Cetindamar, D., \& Hopkins, T. (2008). Enhancing students' responsibility towards society through civic involvement projects. Innovations in Education and Teaching International, 45, 401-410. doi: $10.1080 / 14703290802377273$

Chapdelaine, A., \& Chapman, B. L. (1999). Using community-based research projects to teach research methods. Teaching of Psychology, 26, 101-105. doi:10.1207/s15328023top2602_4

Constantine, M.G., Hage, S.M., Kindaichi, M.M., \& Bryant, R.M. (2007). Social justice and multicultural issues: Implications for the practice and training of counselors and counseling psychologists. Journal of Counseling \& Development, 85, 24-29. doi:10.1002/j.1556-6678.2007.tb00440.x

Constantine, M.G. \& Ladany, N. (2000). Self-report multicultural counseling competence scales: Their relation to social desirability attitudes and multicultural case conceptualization ability. Journal of Counseling Psychology, 47, 155-164. doi:10.1037/0022-0167.47.2.155

Conway, J. M., Amel, E. L., \& Gerwien, D. P. (2009). Teaching and learning in the social context: A metaanalysis of service learning's effects on academic, personal, social, and citizenship outcomes. Teaching of Psychology, 36, 233-245. doi:10.1080/00986280903172969

Cook, A. L., Krell, M. M., Hayden, L. A., Gracia, R., \& Denitzio, K. (2016). Fieldwork using the professional development schools model: Developing a social justice orientation and multicultural competency. Journal of Multicultural Counseling and Development, 44, 176-188. doi:10.1002/ jmcd.12045

Dunlap, M. R. (1998). Methods of supporting students' critical reflection in courses incorporating service. Teaching of Psychology, 25, 208-210. doi:10.1207/s15328023top2503_13 
Fassinger, R. E. (2005). Paradigms, Praxis, Problems, and promise: Grounded theory in counseling psychology research. Journal of Counseling Psychology, 52, 156 -166. doi:10.1037/0022-0167.52.2.156.

Fouad, N. A., Gerstein, L. H., \& Toporek, R. L. (2006). Social justice and counseling psychology in context. In R. L. Toporek, L. Gerstein, N.A. Foud, G. Roysircar, \& T. Israel (Eds.). Handbook for social justice in counseling psychology: Leadership, vision, and action, (pp. 1-16). Thousand Oaks, CA: Sage Publications.

Gurin, P., Nagda, B. R. A., \& Zuniga, X. (2013). Dialogue across difference: Practice, theory, and research on intergroup dialogue. New York, NY: Russell Sage Foundation.

Langseth, M. (2000). Maximizing impact, minimizing harm: Why service-learning must more fully integrate multicultural education. In O'Grady, C. R. (Ed.), Integrating service learning and multicultural education in colleges and universities (pp. 247-262). New York, NY: Routledge.

Lewis, J. A., Arnold, M. S., House, R., \& Toporek, R. L. (2002). ACA advocacy competencies. Retrieved from http://www.counseling.org/Publications/

Micah, L., McCreary, M. L., \& Walker, T. D. (2001). Teaching multicultural counseling prepracticum. Teaching of Psychology, 28, 195-198. doi:10.1207/S15328023TOP2803_05

Mallinckrodt, B., Miles, J. R., \& Levy, J. J. (2014). The scientist-practitioner-advocate model: Addressing contemporary training needs for social justice advocacy. Training and Education in Professional Psychology, 8(4), 303-311.

Murray, C. E., \& Crowe, A. (2016). Counseling advocacy competencies in action: Lessons learned through the See the Triumph campaign. The Journal for Social Action in Counseling and Psychology, 8, 53-69. Retrieved from http://www.psysr.org/jsacp/Murray-v8n1_53-69.pdf

Myers, J.E., Sweeney, T.J., \& White, V.E. (2002). Advocacy for counseling and counselors: A professional imperative. Journal of Counseling and Development, 80, 394-402.

Paquin, J.D., \& Williams, D.O. (2017). Enhancing group facilitation of Intergroup Dialogue using group dynamics research. Conversation hour presented at the 2017 American Psychological Association Convention, Washington D.C, US.

Pieterse, A. L., Evans, S. A., Risner-Butner, A., Collins, N. M., \& Mason, L. B. (2009). Multicultural competence and social justice training in counseling psychology and counselor education: Review and analysis of a sample of multicultural course syllabi. The Counseling Psychologist, 37, 93-115. doi:10.1177/0011000008319986

Ratts, M.J., \& Hutchinson, M. (2009). ACA advocacy competencies: Social justice advocacy at the client/ student level. Journal of Counseling and Development, 87, 269-275. doi:10.1002/j.1556-6678.2009. tb00106.x

Ratts, M. J., Singh, A. A., Nassar-McMillan, S., Butler, S. K., \& McCullough, J. R. (2016). Multicultural and social justice counseling competencies: Guidelines for the counseling profession. Journal of Multicultural Counseling and Development, 44, 28-48. doi:10.1002/jmcd.12035

Singh, A.A. (2010). Teaching social justice advocacy: Using the metaphor of a quilt. Psychology of Women Quarterly, 34, 550-553. doi:10.1111/j.1471-6402.2010.01604.x

Tashakkori, A. \& Teddlie, C. (1998). Mixed methodology: Combining qualitative and quantitative approaches. Thousand Oaks, CA: Sage Publications.

Thomas, R.M. (2003). Blending qualitative and quantitative: Research methods in theses and 
dissertations. Thousand Oaks, CA: Corwin Press.

Tryon, E., \& Stoecker, R. (2008). The unheard voices: Community organizations and service-learning. Journal of Higher Education Outreach and Engagement, 12, 47-60. Retrieved from http://openjournals.libs.uga. edu/index.php/jheoe/article/view/99/87

Vera, E.M., \& Speight, S.L. (2003). Multicultural competence, social justice, and counseling psychology: Expanding our roles. The Counseling Psychologist, 31, 253-272. doi:10.1177/0011000002250634

Warren, C. S. (2006). Incorporating multiculturalism into undergraduate psychology courses: Three simple active learning activities. Teaching of Psychology, 33, 105-109. doi:10.1207/s15328023top3302_5 